Author version: Mar. Georesour. Geotechnol., vol.32(2); 2015; 177-182

\title{
A simple device for sub-sectioning aqueous sediments from the box or spade corer
}

\author{
Anil B. Valsangkar*1
}

National Institute of Oceanography, Dona Paula, Goa- 400 403, India

\begin{abstract}
A simple device has been developed to accomplish the requirement of precise thin sub-sections of the aqueous sediments at ease from the box or spade sub-cores. The device has been successfully tested on board research vessel for the performance and easiness. It is small, sleek, lightweight, portable and cost low. It has few mechanical controls, require $0.25 \mathrm{~m}^{2}$ floor area, and eco- and user friendly. The device can be easily assembled- dissembled, and operated by one or two person. The device is best suitable to obtain précised thin sections for determining various parameters in chemical, biological and geological oceanographic research.
\end{abstract}

* Corresponding author

${ }^{1}$ Permanent address: B-6, Ramnath Building, Ansabhat, Mapusa, Goa-403507, India.

Tel: 91-0832-2255066 (R); e-mail: valsabv50@gmail.com 


\section{Introduction}

The box corer or spade corer collects fairly undisturbed seafloor sediments in a box of 50x50x50 cm or $20 \times 30 \times 40 \mathrm{~cm}$ dimension respectively. Once the corer (box or spade) is operated successfully from the research vessel, the box containing aqueous sediment is detached quickly for sub-sectioning/sampling the sediment. In the next step, the sediment is split in to sub-cores by inserting $50-55 \mathrm{~cm}$ long clean acrylic or PVC liners of different diameter (Figure 1) to facilitate determining different biogeochemical parameters. The sediment in the sub-core is generally sub-sectioned following the push core method. It has been pointed that the push core method and earlier developed sediment extrusion apparatus are usually tedious, time consuming and lack precision due to many technical problem (Valsangkar, 2007). Adopting these methods result in to sub- sectioning/sampling error and sediment mixing. The subsectioning systems used for the gravity and piston core sediments also have been reviewed (Lunne and Long, 2006), and possible errors due to sampling disturbance exerted by sample tube penetration, retrieval, sample extrusion, etc. have been discussed. For example, in piston extruder technique (Kemp et al., 1971), precise extrusion of sediments for small increments is difficult due to involvement diversity of fixtures, whereas in another (Glew, 1988), the apparatus is large, bulky, heavy, and complicated as the method involve movement of components by locking and unlocking of many parts. In yet another sediment sub-sectioning method (Valsangkar, 2007), the apparatus is liable to generate physical strain (shoulder and chest pain), as the steel wheel is required to be rotated manually. Thus it appears that, the progress in the development of sediment sub-sectioning/sampling devices is quite slow. It further points that the sediment sub-sectioning/sampling methods are not fully evolved, which in turn indicates ample scope to modify and develop a simplified sub-sectioning method and apparatus for precision, ease and efficiency. The proposed sediment sub-sectioning/sampling device overcomes all the above mentioned difficulties and at the same time it is simple, small, sleek, light weight, portable, low cost, eco-and user friendly, and extremely useful in obtaining précised fine sub-sections of the sub-core sediments with ease and flexibility of sub-section intervals.

\section{Materials and methods}

\section{Components of device}

The Figure 2 shows different parts of the proposed sediment sub-sectioning/sampling device and a sequence before assembling. The main part of the device consists of a basal plate [3] supported with four rubber buffers [2] at the bottom and a hole [4] in the center to hold $120 \mathrm{~cm}$ long and hollow GI pipe [6]. It is possible to replace the basal plate [3] by a suitable stand or tripod to suit the GI pipe [6]. The 
second important part is a hollow central GI pipe [6] perforated with holes [7] at $2 \mathrm{~cm}$ interval on either side. The GI pipe has a small threaded portion [5] at the bottom and a small projected portion/ pivot [10] on the top. The GI pipe is fixed centrally on the basal plate [3] by inserting the threaded portion [5] through the hole [4] and bolting it with a nut [1] at the bottom of the basal plate [3]. The third part of the device is the sample holder [12] fixed on another small portion of a hollow and perforated GI pipe. The inner diameter (ID) of sample holder [12] is slightly bigger than the outer diameter (OD) of the centrally fixed perforated GI pipe in order to move freely from top to bottom of the perforated GI pipe [6]. The sample holder also has holes [11] at $2 \mathrm{~cm}$ intervals matching similar to those on the central perforated GI pipe [6]. The steel plate on the sample holder top has a rim all along [12] to support the sediment sub-core [16] vertically. The steel plate also has a hole [13] in the center whose diameter equals to ID of the sample holder [12] on the centrally fixed perforated GI pipe [6]. Fourth part of the device is a steel key [8], which is inserted externally through the hole of the perforated GI pipe [6] for locking and unlocking the sample holder [12].position temporarily anywhere on the perforated GI pipe [6]. The key is long enough so that it appears on other side of the perforated GI pipe [6]. The ring(s) [9] of different height $(0.25,0.5,1 \mathrm{~cm}$, etc.) are important part of the device which are chosen as per the sediment sub-sectioning/sampling interval. The ring(s) [9] and the sample holder [12] have same ID and OD, The ring(s) are actually different height cut pieces of hollow GI pipe of the sample holder [12] whose ID is slightly bigger than that OD of the centrally fixed GI perforated pipe [6]. Therefore, these rings remain at the bottom of centrally fixed GI perforated pipe [6]. During sediment sub-sectioning/sampling, particular ring(s) is brought up and placed on a steel key [8] below the sample holder [12]. In reality, the ring(s) reduces the $2 \mathrm{~cm}$ distance between any two holes [7] The main purpose of ring(s) is to displace the sediment on the top of the sub-core [18] equivalent to the height of the ring(s). For convenience, the rin(s) can also be held midway of the GI pipe [6] by using an additional key. The ring(s) thus help to obtain fine scale sediment sub-section(s) [18] above the sub-core [16] (Figure 2). The rings of plastic or flexible material can also be used externally to achieve the purpose.

\section{Accessories}

1) Acrylic core liners: The 50-55 cm long acrylic core liners of different OD (5.6, $12.5 \mathrm{~cm}$, etc.) are important accessory part of the device, used to obtain sediment sub-cores from the box or spade core (Figure 1). The sub-core is mounted on the sample holder (12, Figure 2 ) of the device for sub-sectioning the sediment.

2) PVC disk: A $2.5 \mathrm{~cm}$ thick PVC disk (or stopper or cap) (15, Figure 2) having a small groove (14, Figure 2$)$ of the size of the pivot (10, Figure 2$)$ in the center at base, is another accessory of the 
device. Before removing the sub-core from the box, the PVC disk is inserted at the bottom of the sub-core (Figure 1) and held manually to protect sediment falling from the bottom of the subcore. Because of the groove (14 Figure 2), the sediment sub-core is positioned and remains vertically straight on the pivot [10, Figure 2) at the top of the GI pipe [6, Figure 2).

3) Steel cutter: A round steel cutter or plate (17, Figure 2) is another accessory piece used for sectioning the sediment raised on the top (18, Figure 2$)$ of the sub-core (16, Figure 2$)$. The plate has provided half sharpened edge to cut the sediment. The remaining half portion of the plate has a rim to protect the sediment falling apart. The plate also has a small handle (17, Figure 2$)$ for better grip.

4) Spanner: An adjustable spanner is required to bolt the nut [1] below the basal plate [3] to the threaded portion [5] of perforated GI pipe [6] as shown in Figure 2..

\section{Assembling}

Assembling the parts of the device is easy and the complete sequence is shown in Figure 2. First, the threaded portion [5] of the perforated GI pipe [6] is inserted vertically through the hole [4] of the basal plate [3] and bolted with nut [1] at the bottom. Selected ring(s) [9] (of different heights) equivalent to the sub-sampling interval(s) are then put on the GI pipe [6] from the top to reach to the bottom. For convenience, the ring(s) can be held midway on the GI pipe by using a steel key [8]. Later, the sample holder [12] is placed on the top of the GI pipe [6] and lowered down until the pivot [10] is well exposed. The lowering of the sample holder is stopped by resting it on another steel key [8]. Now, the sediment sub-core [16] with the grooved disk at the bottom is placed vertically on the top of the pivot [10]. In order to begin sub-sectioning/sampling the sediment, it is necessary that the level of the sediment in the sub-core aligns with the top of the acrylic sub-core liner [16]. In case of mismatch, the sample holder and acrylic sub-core liner are lowered down together, and the sample holder is locked with a key [8] when the sediment top levels with the top of the acrylic core liner [16]. The device is now ready for sediment sub-sectioning/sampling.

\section{Sub-sectioning/sampling}

The device can be used unlimited times to obtain the sediment sub-sections of desired interval using accessory of a steel plate/cutter. (17, Figure 2), a steel key (8, Figure 2), and a ring(s) (9, Figure 2). It is also necessary that the steel plate/cutter is washed every time with distilled water, 
1) At $2 \mathrm{~cm}$ interval: The sub-core sediment can be sub-sectioned/sampled at $2 \mathrm{~cm}$ interval easily and quickly by first removing the steel key (8, Figure 2) and inserting it in the next adjacent hole, and simultaneously lowering the sample holder and sub-core liner together to rest it on the key. As the spacing between any two hole is $2 \mathrm{~cm}$, the $2 \mathrm{~cm}$ thick sediment sub-section appears on the top of the core liner (18, Figure 2; Figure 3), which can be cut and collected on a steel plate (17, Figure 2). The procedure is repeated to obtain remaining sections till the end of the sub-core.

2) At $1 \mathrm{~cm}$ interval: In order to obtain sub-sections at $1 \mathrm{~cm}$ interval throughout the sub-core, a ring (9, Figure 2) of $1 \mathrm{~cm}$. is placed above the key (i.e. below the sample holder) every alternate time, and the 1 $\mathrm{cm}$ section of the sediment exposed on the top is sectioned using a steel plate as described above.

3) At $0.5 \mathrm{~cm}$ interval: The $0.5 \mathrm{~cm}$ sediment sections are obtained by placing four rings (each of $0.5 \mathrm{~cm}$ height) together (9, Figure 2) on the key (8, Figure 2) and by removing/releasing the bottommost ring from of the key every time, so as to display the $0.5 \mathrm{~cm}$ sediment section on the top of the sub-core. The sediment thus exposed on the top is sectioned, packed in the plastic bag and numbered. Similarly, other three $0.5 \mathrm{~cm}$ sections are removed and packed. By this way first top $2 \mathrm{~cm}$ sediment is sub-divided in to four parts of $0.5 \mathrm{~cm}$ each. This procedure is repeated for the remaining part of the sediment in the sub-core up to the bottom.

4) At 3, 5, 7, cm interval: The sub-core sediments can be sub-sectioned @ 3,5, 7,cm etc. cm interval using one ring of $1 \mathrm{~cm}$ and following the above procedure. For this purpose the initial key position from the sediment top will be at $4,6,8 \mathrm{~cm}$ etc. respectively and little calculation will help to decide the next key position.

5) Combination of odd and even interval: In the similar way, combination of any sub-section interval is possible; however, the care to be taken in selecting the appropriate size rings.

\section{Results and discussion}

The proposed apparatus/device has been successfully tested and used ${ }^{5}$ for the first time during $38^{\text {th }}$ oceanographic expedition of the Russian research vessel RN A. Boris Petrov (ABP-38) in the Central Indian Basin (CIB) during 2009 (Figure 3). The research vessel was chartered by the Ministry of Earth Sciences (MoES), Government of India, for their Environmental Impact Assessment (EIA) of nodule mining ongoing programme in the CIB. During ABP-38 cruise, the box corer of 50x50x50 cm dimension (NIO, 2009).was used and silty clay sediments were collected from 8 locations. The water depth at these locations varied from 5041 to $5277 \mathrm{~m}$. At each location, the box core sediments were split in to 
number of sub-cores for determining different biogeochemical parameters. Generally, the sub-core were comprised of 9 acrylic liners (5.7 cm OD, $50 \mathrm{~cm}$ length), 5 PVC liners $(12.5 \mathrm{~cm}$ OD, and $50 \mathrm{~cm}$ length), and 2 PVC liners (10 cm OD and $50 \mathrm{~cm}$ length) (Figure 1). The sub-cores were carefully removed from the box by inserting a PVC disk at the bottom. The sub-core was then placed on the top of the device and sub-sectioned/sampled at the required sub-section intervals as per the parameter. The performance of the device was found satisfactory as the sediment sub-sections were suitable for the geochemical (2 cm interval), biogeochemical (1 cm interval), pore-water chemistry (5 cm interval), and sedimentological (combination of $2 \mathrm{~cm}$ and $5 \mathrm{~cm}$ interval) studies. The device was also tested for combination of $0.5,1$ and $3 \mathrm{~cm}$ intervals. Normally, such small sediment sub-sections are required for benthos (meio and micro) and chlorophyll studies.

During ABP-38 cruise, the sediments were recovered at 8 times out of 14 box core operations (57\% success) from total 3 stations (Figure 4$)$, and the big $(12.5 \mathrm{~cm})$ and small diameter $(5.7 \mathrm{~cm})$ sub-cores were sub-sampled for determining different environmental parameters. In order to facilitate comparison of different parameters present in the previous data set, the sediment sub-sampling intervals were retained the same as those adopted for the previous EIA cruises in the area. For determination of common environmental parameters, the sub-core sediments were sub-sampled at $2 \mathrm{~cm}$ interval up to $10 \mathrm{~cm}$ and at $5 \mathrm{~cm}$ interval for the remaining depth (Table 1), and the new method attempted for subsampling the sub-core sediments was comparatively fast, accurate and easy. The maximum length of the sub-core sub-sampled was $38 \mathrm{~cm}$ (Table 2).

The big core liner was sub-sampled at standard intervals for determining sedimentological (sand, silt, clay and clay mineralogy), pore water chemistry ( $\mathrm{pH}$, nitrite, phosphate, silicate, and nitrate), and macro-benthos. The sediment sub-sections were uniform and précised that facilitated to note down the sediment core log and description (Table 3). The sub-samples at standard intervals were also provided for determination of geotechnical/ physical properties (specific gravity, natural water content, wet density and porosity) in shore laboratory.

Extraction of pore waters from the sub-sampled sediments was carried out at two stations (IVBC-18C and IVBC-20A) at $2 \mathrm{~cm}$ interval up to $10 \mathrm{~cm}$ and then $5 \mathrm{~cm}$ interval up to $20 \mathrm{~cm}$ depth. The subsectioned sediments (by new method) were immediately transferred in to centrifuge tubes and centrifuged at $\sim 5000 \mathrm{rpm}$. The supernatant water was collected in he plastic bottles and filtered in Millipore filtration unit through 0.42 microns membrane filters and stored in the deep freezer. The $\mathrm{pH}$ was measured on LABINDIA $\mathrm{pH}$ analyzer immediately after the filtration. The pore waters were analyzed for nutrients and ammonia was measured in selected cores. 


\section{Advantages}

The proposed device has many scientific, technical and social advantages. Technically, device is simple, where the parts are made up of anti rusting material. At any stage, the device is capable of providing combination odd and even sub-sectioning/sampling interval. Further, no ring is required for even number sub-sectioning/sampling interval. Also, the device is not required to be calibrated before the start of operation, because the precision of the sub-section/sample can be confirmed by using an external scale.

The device has very few mechanical controls and can easily be operated by one or two person. It is portable, low cost (<Rs. 2000/-), lightweight (<4 kg), slender and occupies $0.25 \mathrm{~m}^{2}$ floor area. It can be transported easily and can be assembled or dissembled quickly at the site of operation. It is durable, reusable, user- and eco- friendly, and requires no maintenance as wear and tear of the part is negligible. It can be easily transported to the field or on a small boat or on any research vessel.

Scientifically, the device is non-magnetic. It holds the sub-core vertically and does not disturb the physical and/or biogeochemical properties of the sediment. The device provides sediment subsections/samples without contamination and mixing. It also gives an opportunity for close observations at each cross section (i.e. sub-section/sample) to note down the core log. The device is best suitable for conducting research in the field of geological, biological and chemical oceanography, where precise and thin sediment sub-sections/ samples are pre-requisite.

Requirement of less manpower and no physical exertion during the operation are the important advantages among the others.

\section{Conclusions}

A simple device has been fabricated and tested successfully on board Russian research vessel $R / V A$. Boris Petrov during the cruise ABP-38 in the Central Indian Basin to obtain fine scale subsections/samples from the box core sediment. The sediment sub-sections were obtained with speed, ease and precision. The device has many scientific, technical, and social advantages besides being portable, durable, low cost, lightweight, non-voluminous, and eco-and user- friendly. The device is most appropriate in obtaining accurate sub-sections of box or spade core sediments, which are basically required to carry out biogeochemical research in the oceanography. 


\section{Acknowledgements}

The Ministry of Earth Sciences (MoES), New Delhi, provided funds under the project, `Environmental Impact Analysis of mining of marine minerals (EIA)'. Author thanks Mr. P. Pawaskar and R. Uchil for preparing the figures. This is patent application no. 0068NF2010, filed in India on 11-11- 2010. This is NIO (CSIR) contribution no. ----

\section{References}

Glew, J.R. 1988. A portable extruding device for close interval sectioning of unconsolidated core samples. Journal of Paleolimnology 1: 235-239

Kemp, A.L.W., H.A. Savile, C.B. Gray, and A. Mudrochova. 1971. A simple corer and a method for sampling the mud-water interface. Limnology \& Oceanography 16: 689-694.

Lunne, T., and M. Long. 2006. Review of long seabed samplers and criteria for new sampler design. Marine Geology, 226: 145-165.

NIO, 2009. R/V Akademik Boris Petrov, Cruise 38 (07 September- 07 October). Goa: National Institute of Oceanography. (Unpublished).

Valsangkar, A.B., 2007. A device for finer scale sub-sectioning of the aqueous sediments. Curent Science 92: 428-431. 


\section{Figure Captions}

Figure 1. Different diameter pvc and acrylic core liners (50 cm long) inserted in the box core sediments at station no. IVBC-20A during ABP-38 cruise of. $R / V$ Akademik Boris Petrov.

Figure 2. Front view of the device. 1- Nut, 2- buffer, 3- basal plate, 4- hole, 5- threaded portion, 6- perforated hollow GI pipe, 7- holes @ 2 cm interval on the GI pipe, 8- steel key, 9ring(s), 10- pivot or projected portion, 11- holes @ 2 cm interval on sample holder pipe, 12sample holder, 13- hollow portion of sample holder pipe, 14- groove in the PVC disk, 15- PVC disk or stopper or cap, 16- sub-core with sediment, 17- steel cutter or slicer or plate, 18- subsection of the sub-core sediment.

Figure 3. Operation of the sub-sectioning/sampling device during ABP-38 cruise. Note that the sub-core remain vertical on the sample holder, the sample holder is locked on a sell key below, and $2 \mathrm{~cm}$ sediment sub-section appeared on the top.

Figure 4. Cruise track and sampling stations during ABP-38.

\section{Table Captions:}

Table 1: Total length (depth) of sediment sub-cores (cm) sub-sampled (sectioned) for determining various parameters during ABP-38 cruise.

Table 2: Number of sediment sub-cores shared for determining common parameters during ABP-38 cruise.

Table 3: Core log of the sediments collected during ABP-38 Cruise. (IV- Intermediate seasonal variation, BC- Box Core) 
Table 1: Sediment sub-cores shared for determining common parameters during ABP-38 cruise.

\begin{tabular}{|c|c|c|c|}
\hline & Parameters & $\begin{array}{c}\text { Small cores } \\
(5.7 \mathrm{~cm} \mathrm{dia.})\end{array}$ & $\begin{array}{c}\text { Big cores } \\
(12.5 \mathrm{~cm} \mathrm{dia.})\end{array}$ \\
\hline 1 & Sedimentology & & 1 \\
\hline 2 & Geotechnical properties & 2 & \\
\hline 3 & Sediment geochemistry & 2 & 1 \\
\hline 4 & Pore water chemistry & & \\
\hline 5 & $\begin{array}{c}\text { Microbiology \& } \\
\text { Biochemistry }\end{array}$ & 3 & 2 \\
\hline 6 & Macro-brnthos & & \\
\hline 7 & Meio-benthos & 1 & \\
\hline 8 & Repository & 1 & \\
\hline
\end{tabular}

Table 2: Total length (depth) of sediment sub-cores $(\mathrm{cm})$ sub-sampled (sectioned) for determining various parameters during ABP-38 cruise.

\begin{tabular}{|c|c|c|c|c|c|c|}
\hline \multirow{2}{*}{$\begin{array}{c}\text { Decipline/ } \\
\text { Parameters }\end{array}$} & \multicolumn{5}{|c|}{ Station no. } \\
\hline IVBC-18A & IVBC-18C & IVBC-18D & IVBC-18E & IVBC-19D & IVBC-20A \\
\hline Microbiology & 13 & 36 & & & & 26 \\
\hline Mycology & 13 & 38 & & & & 25 \\
\hline Biochemistry & & 36 & & & & 25 \\
\hline Geochemistry & & 37 & & & & 27 \\
\hline Micro-benthos & & 35 & 38 & 32 & 18 & 23 \\
\hline Meio-benthos & & 35 & 38 & 32 & 18 & 24 \\
\hline Geotechnology-1 & 38 & & & & 27 \\
\hline Geotechnology-2 & & 38 & & & & 27 \\
\hline $\begin{array}{c}\text { pH and Pore water } \\
\text { chemistry }\end{array}$ & & 20 & & & & 20 \\
\hline CNP & & 36 & & & & \\
\hline Sedementology & & 34 & & & & 26 \\
\hline Repository & & 35 & & & & 27 \\
\hline
\end{tabular}

IV- Intermediate seasonal variation, BC- Box Core; CNP- Carbon-Nitrogen- organic phosphorus 
Table 3: Core log of the sediments collected during ABP-38. (IV- Intermediate seasonal variation, BCBox Core)

\begin{tabular}{|c|c|c|}
\hline \multicolumn{3}{|c|}{ Station No. } \\
\hline IVBC-18C & IVBC-19 & IVBC-20A \\
\hline $\begin{array}{l}0-6 \mathrm{~cm} \text { : } 5 \text { YR3/4, uniform in } \\
\text { moderate brown. } \\
\text { 6-13 cm: Lenses of } \\
\text { (10YR5/4) in a } \\
\text { matrix of light shade } \\
\text { of moderate brown } \\
\text { (5YR3/4). } \\
13-39 \mathrm{~cm} \text { : Lenses of } \\
\text { mottling of light } \\
\text { shade of 10YR5/4 in } \\
\text { moderate brown } \\
5 Y R 3 / 4 .\end{array}$ & Disturbed sediment. & $\begin{array}{l}\text { 0-3 cm: Uniform moderate brown } \\
\text { (5YR3/4) and nodules. } \\
\text { 3-27 cm: Thin bands of } \\
\text { Moderate yellow brown } \\
(10 Y R 5 / 4) \text { at } 7 \text { and } 12 \\
\text { cm in a matrix of } \\
\text { moderate brown } \\
\text { (5YR3/4). } \\
\text { At } 22 \mathrm{~cm} \text { : Lenses of moderate } \\
\text { yellow brown. }\end{array}$ \\
\hline
\end{tabular}

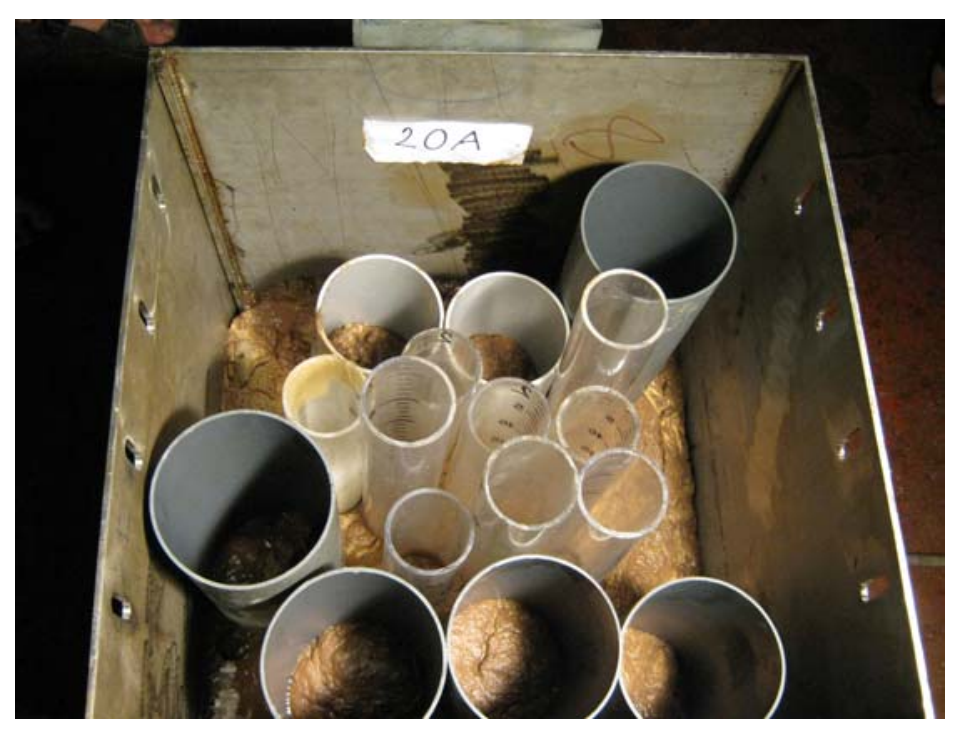

Figure 1.

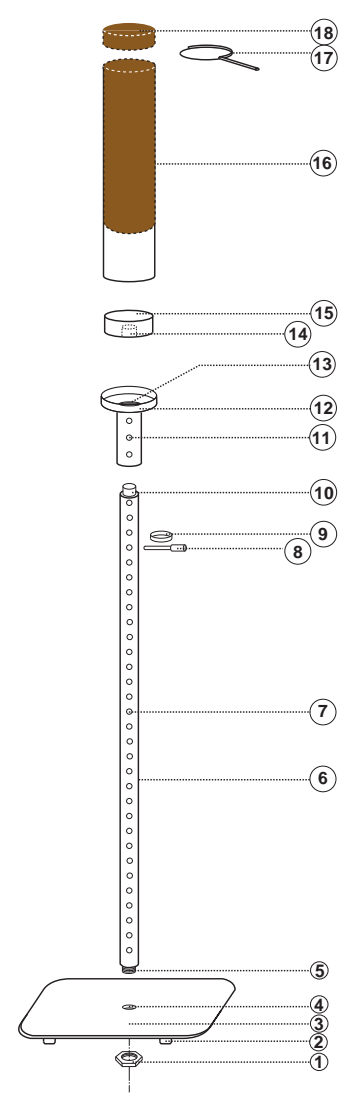

Figure 2. 


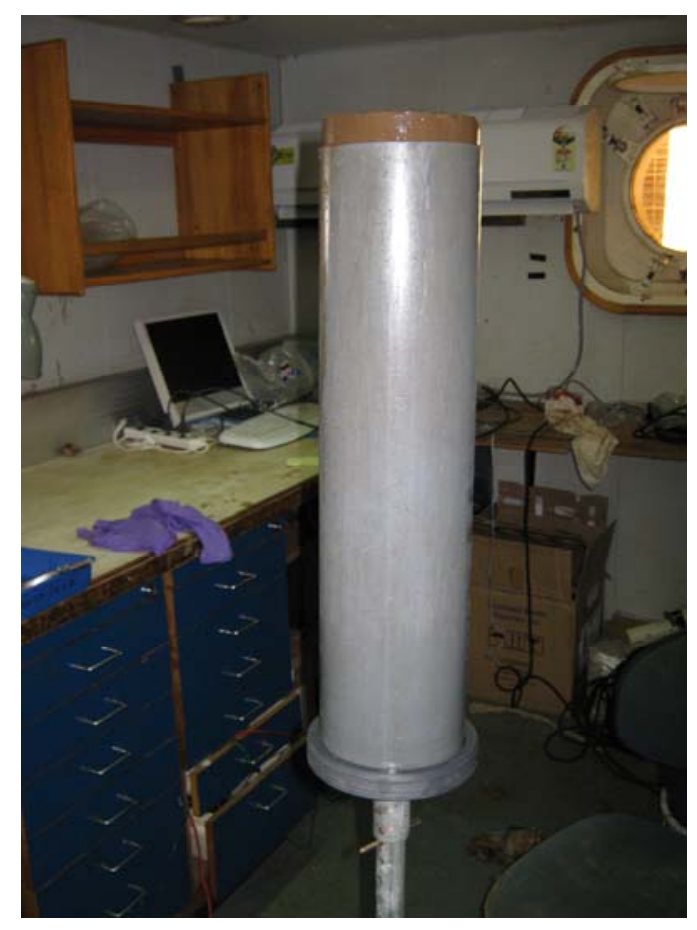

Figure 3

TRACKS CRUISE ABP38

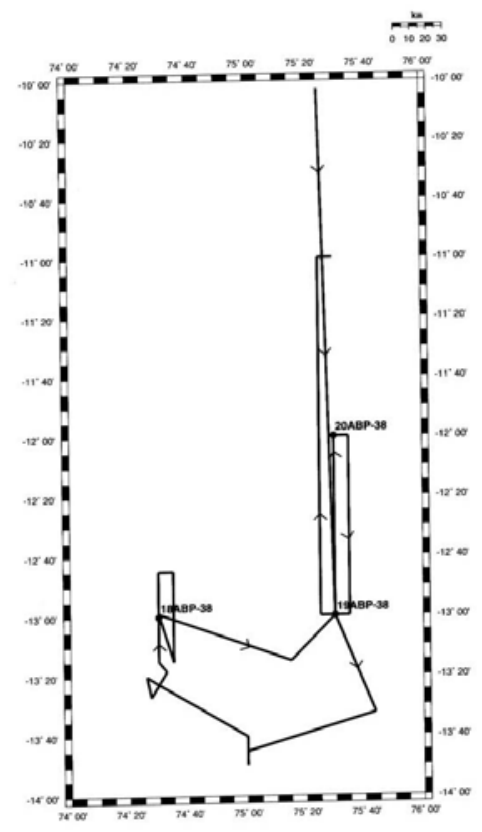

Figure 4. 